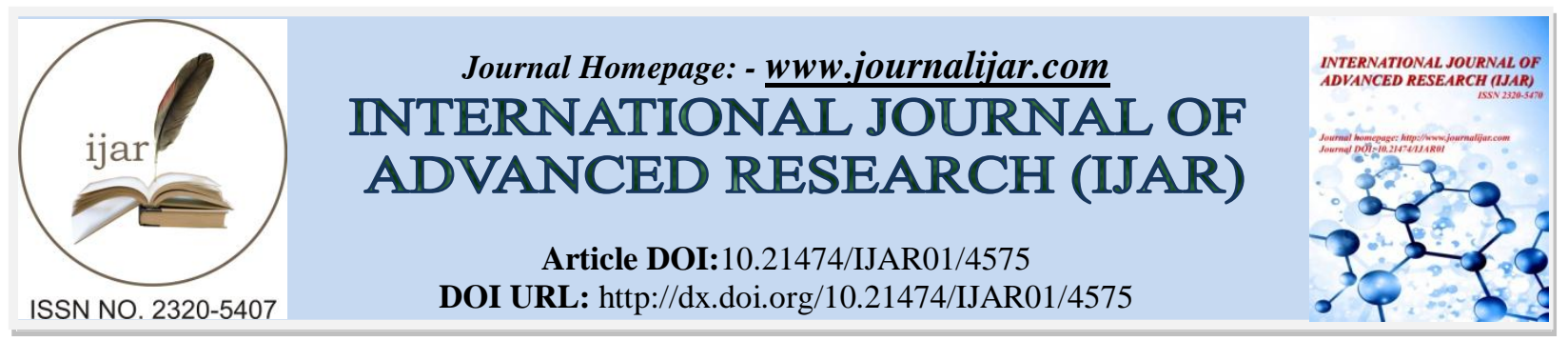

RESEARCH ARTICLE

\title{
MACRONUTRIENT STATUS OF DIFFERENT LAND USES IN SOILS OF NORTH WESTERN HIMALAYAS, H.P-INDIA.
}

\section{Ravinder Kumar ${ }^{1}$ and S. S. Paliyal ${ }^{2}$.}

1. Ph.D Doctoral Scholar, Department of Soil Science H.P. Krishi Vishavavidyala, Palampur 176062, India.

2. Principle Scientist, (Soil Science) Krishi Vigyan Kendra, Sirmour at Dhaulakuan (H.P.) 173031.

\section{Manuscript Info}

Manuscript History

Received: 22 April 2017

Final Accepted: 24 May 2017

Published: June 2017

Key words:-

Soil fertility, Macronutrient, North

Western Himalaya-H.P

\section{Abstract}

The present study is an attempt to assess macronutrient (N, P, and $\mathrm{K}$ ) status in soils of North Western Spiti Valley Himalayas by calculating nutrition Index (NI). The study is based on 71 representative surface $(0-15 \mathrm{~cm})$ and subsurface $(15-30 \mathrm{~cm})$ soil samples were collected randomly from cultivated and pasture lands using stainless steel spatula, shovel and spade. Based on results, soils were found sandy loam to sandy clay loam in texture and slightly alkaline in their reaction ( $\mathrm{pH}$ 7.7-8.1). Available $\mathrm{N}$ contents were in low category whereas, $\mathrm{P}$ and $\mathrm{K}$ were found in medium category. Macronutrients decreased in the sub-surface soils mainly due to continuous addition of organic matter and frequent applications of fertilizers. The study shall be of great significance not only in understanding the agricultural resource base of the region but will also provide a new strategy to curb malnutrition which is prevalent in the area and will develop focus for its optimum use.

Copy Right, IJAR, 2017,. All rights reserved.

\section{Introduction:-}

In India, cold desert comes under the trans Himalayan zone which is approximately 1,03,11,300 ha. These are arid areas not affected by the Indian monsoon because they lie in the rain shadow of the Himalayan mountain systems. Scanty rainfall, massive snowfall, high wind velocity, extreme temperature conditions from low to high, sparse vegetation, high UV radiation, intense solar radiation and extremely xeric conditions are the common features of this region (Devi and Thakur, 2011). Spiti region is a separate geographical unit separated from Lahaul by Kunzum pass (4551 m amsl), a typical cold arid mountain much more difficult with a lowest point at $3050 \mathrm{~m}$ amsl. The major area is under barren and uncultivated land (77\%) and pastures (22\%). Major crops of the valley are Pea, Barley, Potato, Wheat, Rajmash, and Apple. Pea and apple are the two major cash crops of the valley. Cultivation is possible only in summer (April to September) under assured irrigation provided by glacial melt. Soil fertility is determined by the presence or absence of nutrients i.e. macro and micronutrients that are not uniformly found in the soils (Wajahat et al, 2006) leading some soils surplus and other defict in terms of concentration. These macro nutrients are essential for the life cycle of normal growth of plants, deficiency of which can be corrected by supplying the elements (Kolley, 1993). Nutrients are available as ions in three forms i.e. ions held as colloidal particles, ions absorbed on colloidal surface and ions in solution form (Kanth and Rather, 2003). Of these three forms, those in solution form are the most readily available to plants (David, 1977). Nutrients are continuously removed from the soils by cropping (Young, 1976) in addition to losses by runoff (Kirby and Morgan, 1980) and even a high fertile soil is exhausted of reserve nutrients, as the crops are grown continuously. It was estimated that about 4.17 million tons of 
Nitrogen, 2.13 million tons of phosphorus and 7.42 million tons of potassium are removed annually by agricultural cropping in India (Biswas and Mukerjee, 1994), thus affecting the soil fertility as it depicts a positive association with plants like rice (Zargar, 2009). Out of the 16 plant nutrients, Nitrogen (N), Phosphorus (P) and Potassium (K) are referred as macronutrients; as they are required in large quantities for growth, increase plant productivity, leaf and grain yield and also help in the occurrence, diversity, distribution, and relative abundance of species (Nonzom, S., and Sumbali, G., 2014). Similar is the case with micronutrients like Zn, and Mn deficiency can cause nutritional imbalance in the soils which may results in significant reduction in the productivity of the crops (wani et al, 2014). Almost entire habitation and cultivated lands are along the river Spiti and its tributaries but river water is totally untapped or not used for irrigation purposes. Vast area lying waste can be put under cultivation if river water be used for irrigation. Due to scanty information on soil fertility (Parmar et al. 1999; Sharma and Kanwar, 2010), the present investigation was undertaken to delineate the soils of various land uses of the valley for physico- chemical characteristics and available macro nutrients.

Fig.1:- Map showing sampling site in Spiti Valley

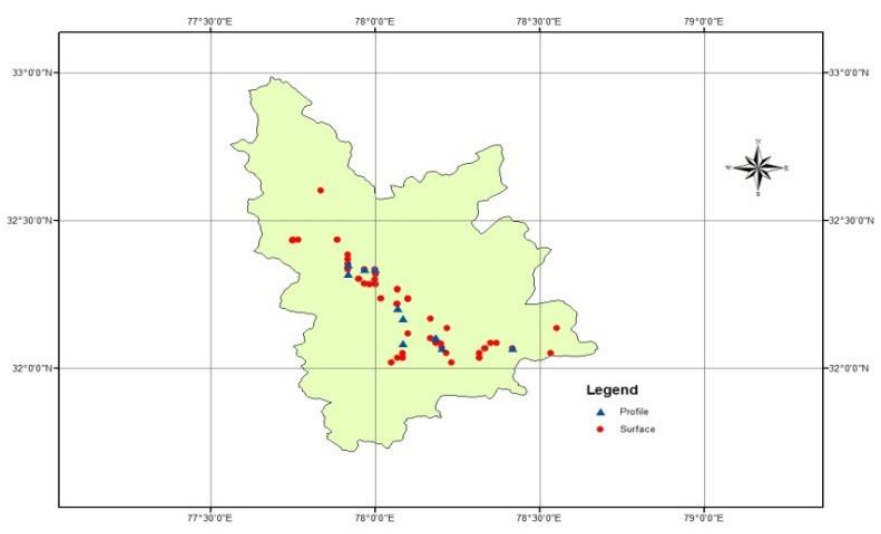

\section{Material and Method:-}

This study was designed to determine the status of macronutrients in agriculturally fertile soils of Northwestern Himalayas. The study area was delineated into 71 sites and profile site ranging from 3144 to 4600 (fig.1) showing 71 sites that were selected for the study across different altitudes. Represented soil samples were collected with wooden tools to avoid any contamination of the soils. Three to five pits were dug for each sample. From each pit sample was collected at a depth 0-30 cm. A composite sample of about $1 \mathrm{~kg}$ was taken through mixing of represented soil sample. All composite samples were dried, ground with wooden mottle and passed through $2 \mathrm{~mm}$ sieve. After sieving all the samples were packed in the labeled polythene bags for laboratory investigations. Of the six macro nutrients i.e. $\mathrm{Ca}, \mathrm{S}, \mathrm{Mg}, \mathrm{N}, \mathrm{P}, \mathrm{K}$, present in the soil $\mathrm{N}, \mathrm{P}$ and $\mathrm{K}$ are required by the plants in relatively large quantities and thus are known as primary nutrients. Soil tests were done for NPK at soil testing laboratory, Post Graduate Soil laboratory CSKHPKV, Palampur by using following respective methods:

1. $\mathrm{pH}$ by standard $\mathrm{pH}$ meter in a 1:2 soil-water suspension.

2. Organic carbon (OC) by Walkley and Black rapid titration method (1934).

3. Available nitrogen (N) by Alkaline Permanganate Method (Subbiah and Asija, 1956).

4. Available phosphorus (P) by Olsen's Method (1954).

5. Available potassium (K) by flame photometry as described by Jackson, 1973.

Based on the content of NPK in the soil, was categorized into fertility classes as low, medium and high as per the following table:

Table 1:- Rating chart for soil test values

\begin{tabular}{|c|c|c|c|}
\hline Nutrients & Low & Medium & High \\
\hline $\mathrm{N}(\mathrm{kg} / \mathrm{ha})$ & $112-124$ & $225-560$ & $561-840$ \\
\hline $\mathrm{P} 2 \mathrm{O} 5(\mathrm{~kg} / \mathrm{ha})$ & $4-10$ & $11-25$ & $>25$ \\
\hline $\mathrm{K} 2 \mathrm{O}(\mathrm{kg} / \mathrm{ha})$ & $47-116$ & $117-280$ & $281-467$ \\
\hline
\end{tabular}

Source: Practical manual Soil Science, CSKHPKV, Palampur. 
Nutrition index was then computed by applying the formula: Nutrition Index $(\mathrm{NI})=\mathrm{NL}+2 \mathrm{Nm}+3 \mathrm{NhNL}+\mathrm{Nm}+\mathrm{Nh}$ Where NL, NM, NH are the number of soil samples falling in the category of low medium and high nutrient status as per the rating chart for the soil test values. Values of 1, 2, and 3 are the weights given to low, medium and high soil category respectively (Biswas and Mukerjee -1994).

Table 2:-Soil Fertility Class.

\begin{tabular}{|c|c|c|c|}
\hline Nutrients & Low & Medium & High \\
\hline $\mathrm{N}(\mathrm{kg} / \mathrm{ha})$ & $<5$ & $5-75$ & $>75$ \\
\hline $\mathrm{P} 2 \mathrm{O} 5(\mathrm{~kg} / \mathrm{ha})$ & $<10$ & $10-25$ & $>56$ \\
\hline $\mathrm{K} 2 \mathrm{O}(\mathrm{kg} / \mathrm{ha})$ & $<120$ & $120-280$ & $>280$ \\
\hline
\end{tabular}

Source: USAID, New Delhi, p.85

\section{Results and Discussion:-}

The study clearly depicts that fertility status in terms of macro nutrients like NPK varies from high to very low with interzonal variations. The available nitrogen content of surface soils (Table 3) of Spiti valley under cultivated lands (annual crops), cultivated lands (apple plantation) and pasture lands ranged from 109 to 407, 188 to 256 and 125 to $250 \mathrm{~kg} \mathrm{ha}^{-1}$, respectively. However, in the sub-surface layers, its values varied from 78 to 376 for cultivated lands (annual crops), 188 to 256 for cultivated lands (apple plantation) and 104 to $334 \mathrm{~kg} \mathrm{ha}^{-1}$ for pasture lands (Table 4). As such available nitrogen was low to medium under all the three land uses. The surface soils were having comparatively higher nitrogen content than the subsurface soils and the cultivated land (apple plantation) have more available nitrogen in comparison to cultivated lands (annual crops) and pasture lands which might be due to continuous addition of organic matter and frequent applications of nitrogenous fertilizers in orchards. These results authenticated the earlier findings who have also reported higher available $\mathrm{N}$ content at the surface and a decreasing trend with depth (Singh, 2012). Similarly, the value of phosphorus content ranged from 4 to 82,20 to 53 and 13 to $80 \mathrm{~kg}^{-1}$ for the surface soils under cultivated lands (annual crops), cultivated lands (apple plantation) and pasture lands, respectively. In subsurface soils the corresponding values were 8 to 89,20 to 53 and 17 to $31 \mathrm{~kg} \mathrm{ha}^{-1}$ under respective land uses. Average available P content was almost similar in all land uses in Spiti valley. Similar were the findings of (Parmar et al. 1999) and (Sharma and Kanwar, 2010). So was found in the concentration levels of Potassium (K) in surface horizons under cultivated lands (annual crop), cultivated lands (apple plantation) and pasture lands were 22 to 260,41 to 108 and 94 to $238 \mathrm{~kg} \mathrm{ha}^{-1}$, respectively whereas, in the sub-surface layers these values varied from 79 to 287,41 to 108 and 98 to $260 \mathrm{~kg} \mathrm{ha}^{-1}$ for corresponding land uses. As such, the soils under study were low to medium with respect to available potassium status. High potassium in the pasture lands is due to the presence of yellow to brown coloured cretaceous age sand stone containing glauconite which is a potash rich mineral (Sharma and Singh, 1991). The fertility status decreases with increasing altitude (Lone and et al. 2013) which is attributed to change in slope from gentle to steep and increase in the intensity of soil erosion as was revealed by (Bhat and Kanth, 1991). The interzonal variations are quite high in all the nutrients phosphorus depicts more than 40 percent variation which is attributed to immiscible charter of phosphorus loss, due to leaching is minimum as compared to its counterparts like nitrogen and Potassium which reveals many folds variations as the soils of Spiti valley in general and soils of North Westren Himalaya in particular had under gone tremendous change as change in the land use and cover and practicing of agriculture has been modified at large.

So these deficiencies can be overcome by using modern biofertilizer abundantly taken into consideration the requirement of the soil both in quantity as well as quality approved by the agriculture department from time to time, besides manuring to increase the nutrient balance. The mono crop culture practiced at higher altitudes should be replaced by mixed cropping or HYV seeds to bring home the benefits the management of soils.

Table 3:- Range \& mean values of available macronutrients in surface soils $(0-15 \mathrm{~cm})$ under different land uses in Spiti valley

\begin{tabular}{|c|c|c|c|}
\hline & \multicolumn{3}{|c|}{ Available (kg ha ${ }^{-1}$ ) } \\
\cline { 2 - 4 } & N & P \\
\hline \multicolumn{4}{|c|}{ Cultivated lands (annual crops) } \\
\hline Range & $109-407$ & $4-82$ & $22-260$ \\
\hline Mean & 182 & 37 & 127 \\
\hline SD \pm & 50.99 & 21.64 & 39.95 \\
\hline \multicolumn{4}{|c|}{ Cultivated lands (apple plantation) } \\
\hline
\end{tabular}




\begin{tabular}{|c|c|c|c|}
\hline Range & $188-256$ & $20-53$ & $41-108$ \\
\hline Mean & 228 & 35 & 80 \\
\hline SD \pm & 29.17 & 13.57 & 28.70 \\
\hline \multicolumn{4}{|c|}{ Pasture lands } \\
\hline Mean & $125-250$ & $13-80$ & $94-238$ \\
\hline SD \pm & 196 & 39 & 166 \\
\hline
\end{tabular}

Table 4:- Range and mean values of available macronutrients in subsurface soils $(15-30 \mathrm{~cm})$ under different land uses in Spiti valley

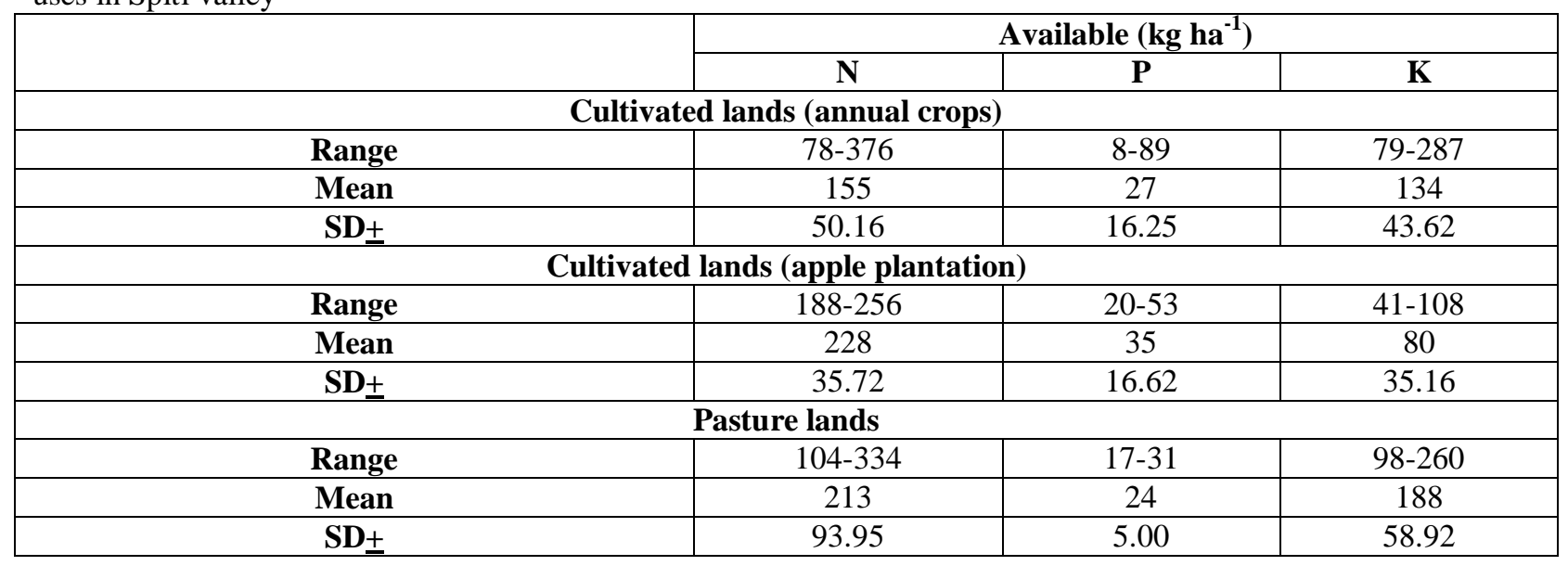

\section{Acknowledgement:-}

The authors are highly thankful to Dr. R.S Rana. Geo Information Centre, CSK H.P.K.V, Palampur, Soil PG Lab assistant for heartfelt help and coordinal support in guiding the authors in a right direction.

\section{Literature Cited:-}

1. Biswas, T. D. \& Mukerjee, S. K. 2001. Textbook of Soil Sciences. Tata McGraw-HillDavid, B. 1977.Soils, Sources and Methods in Geography, Butterworth and Co publishers London.

2. Devi, U. and Thakur, M. 2011.Exploration of Ethno Botanical Uses of Some Wild Plants from Cold Desert of Himachal Pradesh. Asian Journal of Experimental and Biololical Science.2(2): 362-366

3. Jackson, M.L. 1973.Soil chemical analysis. Prentice Hall, India Pvt. Ltd., New DelhiKanth, T.A. and Bhat M.S. 1991. Soil Erosion Intensity Zones in Kashmir Valley, Transaction Institute of Indian Geographers, Vol. 13, No. 2, July, 1991, Pp. 141-48.

4. Kirkby, M. J and Morgan, R.P. 1980. Soil Erosion, John Willey and Sons, New York Kolley, A. K. 1993. Basic Concepts of Soil science, Wiley Eastern Limited, New Delhi

5. Nonzom, S., and Sumbali, G. 2014. Impact of Some Ecological Factors on the Occurrence and Distribution of Mitosporic Fungi in the Cold Desert of Ladakh (India), International Journal of Pharmaceutical Science Invention, Vol. 3 (10) Pp.32-40

6. Olsen, S.R., Cole, C.V., Watanave, F.S. and Dean, L.A. 1954. Estimation of available phosphorus by extraction with sodium bicarbonate. US Department of Agriculture, Citric. p 939

7. Parmar, D.K., Sharma, V., Sharma, K.D. and Sharma, T.R. 1999. Micronutrient status of vegetable growing pocket in cold desert areas of Himachal Pradesh. Journal of the Indian Society of Soil Science 47(2):280-283

8. Sharma, V., and Kanwar, B.B. 2010. Copper status and its relation with soil properties in pea growing soils of high hills dry temprate zone of Himachal Pradesh. Indian Journal of Agricultural Research 44(1): $32-37$

9. Singh, S. 2012. Delineation of secondary and micronutrients in arable lands of Sirmour District in HP. M.Sc Thesis. Department of Soil Science, CSK Himachal Pradesh Krishi Vishvavidyalaya, Palampur, India. p140

10. Subbiah, B.W. and Asija, G.L. 1956. A rapid procedure for the estimation of available nitrogen in soils. Current Science 25: 259-260

11. Wajahat N., Perveen S. and Saleem I. 2006. Status of Micronutrients in Soils of District Bhimber (Azad Jammu and Kashmir) Vol. 1, No. 2, Journal of Agricultural and Biological Science Wani, Mushtaq, A. M., Zahid and 
Nazir, S., 2014. Spatial variability of DTPA Extractable Cationic Micronutrients in Northern part of lesser Himalayas using GIS Approach, 115th Esri India User Conference. Geo-enabling Digital India Pp 1-14

12. Young, A. 1976. Tropical soils and soil Survey, Cambridge University Press, Cambridge.

13. Zargar R., 2009. Relationship between some macronutrients of paddy growing soils of Kashmir and their contents in rice plants, Environment and Ecology Vol. 27 No. 2A Pp. 885-887. 